\title{
Plasma within Templates: Molding Flexible Nanocrystal Solids into Multifunctional Architectures
}

\author{
Arya Ghadimi, Ludovico Cademartiri, Ulrich Kamp and Geoffrey A. Ozin* \\ Materials Chemistry and Nanochemistry Research Group, Center for Inorganic and Polymeric \\ Nanomaterials, Chemistry Department, University of Toronto, 80 St. George Street, Toronto, \\ Ontario, Canada M5S $3 \mathrm{H} 6$
}

\section{Materials and Methods:}

$\underline{\mathrm{PbS} \text { Synthesis and Purification: }}$

The synthesis was a slight modification of previously reported routes ${ }^{1}$. In brief, one gram of $\mathrm{PbCl}_{2}(98 \%)$ was poured into $1.93 \mathrm{~g}$ of stirring oleylamine (OLA) under $\mathrm{N}_{2}$ flow. The mixture was heated to $100{ }^{\circ} \mathrm{C}$, the reaction flask sealed with a rubber septum, and vacuum applied for $5 \mathrm{~min}$. The flask was reopened, the $\mathrm{N}_{2}$ flow restored, and the temperature increased to $120^{\circ} \mathrm{C}$, where it was left for $30 \mathrm{~min}$, always under vigorous stirring. The S precursor solution was prepared in the meantime by adding $0.0115 \mathrm{~g}$ of elemental $\mathrm{S}$ to $0.2 \mathrm{~g}$ of OLA. The $\mathrm{S}$ solution was then injected at room temperature into the stirring $\mathrm{PbCl}_{2}$-OLA gel. The temperature was stabilized to $100{ }^{\circ} \mathrm{C}$ for the subsequent growth. The samples were collected with a syringe at times varying between 8 and 16 minutes and rapidly quenched into cold hexane in $15 \mathrm{~mL}$ centrifuge tubes. The tubes were centrifuged for 15 min to precipitate the excess $\mathrm{PbCl}_{2}$ precursor. A minimum amount of ethanol was added to the supernatant to induce precipitation of the nanocrystals. The solutions were centrifuged, the supernatant was discarded, and the precipitate was redispersed in hexane.

To further purify the nanocrystals we used two strategies: one involving oleic acid (OA) and the other involving acetone. In the first case we added $200 \%$ in volume of OA to the hexane dispersions of $\mathrm{PbS}$ nanocrystals, and the samples were shaken for $5 \mathrm{~min}$, after which they were centrifuged. The supernatant was discarded, and the nanocrystals were redispersed into hexane. The nanocrystals were then further precipitated twice with ethanol and redispersed in hexane to remove any further trace of ligands. After some time, most traces of $\mathrm{PbCl}_{2}$ had precipitated, and they were separated by centrifugation at $3000 \mathrm{rpm}$ for $1 \mathrm{~h}$.

In the latter case precipitation was obtained by using acetone as nonsolvent. In case of increasing acetone addition the first to precipitate is the excess $\mathrm{PbCl}_{2}$ precursor. Then the nanocrystals precipitate and at last the $\mathrm{S}$ precursor precipitates. In this way, by controlling the amount of acetone added, one can almost completely separate the nanocrystals from the excess precursors. This latter methodology gives highly pure nanocrystal; these nanocrystals, however, lack some colloidal stability and thus are 
somewhat sensitive to dilution. All chemicals were purchased from Aldrich unless otherwise stated.

\section{$\underline{\mathrm{CoFe}}_{2} \underline{\mathrm{O}}_{4} \underline{\text { Synthesis and Purification: }}$}

The synthesis of $\mathrm{CoFe}_{2} \mathrm{O}_{4}$ nanocrystals was performed using exactly the route reported by Sun et al. involving the thermal decomposition of $\mathrm{Co}$ and $\mathrm{Fe}$ acetylacetonates in high boiling ethers in the presence of oleic acid, oleylamine and 1,2-hexadecanediol ${ }^{2}$.

\section{Nanorod Synthesis:}

\section{Alumina Membrane Hydrophobization:}

Alumina membranes were hydrophobized using octadecyltrichlorosilane (OTS) purchased from Sigma-Aldrich, which was of technical grade and over $90 \%$ pure. To enhance the room-temperature reaction between OTS and alumina, the membranes were subjected to $5 \mathrm{~W}$ air plasma generated by the Harrick Plasma Cleaner/Sterilizer PDC3XG connected to a Duo-Seal Vacuum Pump manufactured by The Welch Scientific Co. The membrane was treated in plasma for 10 minutes and then submerged in $10 \mathrm{~mL}$ of a $10 \%(\mathrm{~V} / \mathrm{V})$ solution of OTS in hexane and gently shaken for $5 \mathrm{~min}$. During this 5-minute treatment, the OTS solution containing the membranes was sonicated for $2 \mathrm{~s}$ in a $60 \mathrm{~W}$ bath to dislodge any air bubbles blocking the nanochannels. The membranes were then taken out of the OTS solution and submerged successively in two $10 \mathrm{~mL}$ hexane baths, the first time with $2 \mathrm{~s}$ of sonication, to remove any unreacted OTS.

\section{Alumina Membrane Infiltration:}

The membrane was attached to a glass tube using the Metalset A4 two-part epoxy cement manufactured by Smooth-On Inc, and the epoxy was allowed to cure for $3 \mathrm{hrs}$., see Figure $1 \mathrm{~b}$. The glass tube was $8 \mathrm{~cm}$ long and had an outer diameter of $13 \mathrm{~mm}$, matching the diameter of the alumina membrane. The other end of the tube was capped with a septum and reinforced with a wire tie to ensure the septum seal was airtight. The nanocrystal solution was injected through the septum and the tube was kept sealed until all the solvent had evaporated.

In case of $\mathrm{PbS}, 0.5 \mathrm{~mL}$ of concentrated nanocrystal solution (concentration on the order of $10^{16}$ dots/L according to reported extinction coefficients ${ }^{3}$ in hexane was diluted with $1.5 \mathrm{~mL}$ of hexane and injected into the infiltration setup. All the solvent evaporated in approximately 90 min.; subsequently, the septum was removed and the membrane was allowed to air-dry overnight.

In case of $\mathrm{CoFe}_{2} \mathrm{O}_{4}, 0.3 \mathrm{~mL}$ of the concentrated nanocrystal solution was diluted with 1.2 $\mathrm{mL}$ of hexane and the infiltration was carried out as above. 
To obtain the mixed $\mathrm{CoFe}_{2} \mathrm{O}_{4}-\mathrm{PbS}$ nanorods, $0.15 \mathrm{~mL}$ of the $\mathrm{CoFe}_{2} \mathrm{O}_{4}$ and $0.35 \mathrm{~mL}$ of the $\mathrm{PbS}$ concentrated solutions were mixed and diluted with $0.7 \mathrm{~mL}$ of hexane. The infiltration was performed as above.

Nanocrystal Plasma Polymerization and Release of Nanocrystal Nanorods:

Once infiltrated and dry, the membranes were removed from the glass tube and treated in a $5 \mathrm{~W}$ air plasma, under abovementioned conditions, for 48 hours. Subsequently each sample was placed on a glass slide and the alumina membrane was selectively dissolved in a $250 \mu \mathrm{L}$ drop of $1 \mathrm{M} \mathrm{NaOH}_{(\mathrm{aq})}$. The dissolution took approximately 30 min., after which the nanocrystal nanorods were washed with doubly distilled water until the washes were neutral. The liberated nanorods were then allowed to air-dry.

\section{Inverse Opal Synthesis:}

Self-assembly of the Latex Opal:

Polystyrene colloids were synthesized in a variety of sizes by surfactant-free emulsion polymerization. The colloids were deposited by low-pressure evaporation-induced selfassembly as previously reported ${ }^{4}$.

\section{Infiltration of the Opal:}

The opals were sandwiched between two glass slides by allowing a drop of nanocrystal dispersion to diffuse in the gap between the two glass slides, effectively squeezing the opal between them. The construct was then immersed completely in concentrated dispersions of $\mathrm{PbS}$ or $\mathrm{CoFe}_{2} \mathrm{O}_{4}$ nanocrystals in octane. Evaporation of the dispersion induced assembly within the voids of the opal.

\section{Electron Microscopy:}

The electron micrographs were obtained using the Hitachi S-5200 and the higher resolution Hitachi HD-2000 SEM/TEM. Low magnification S-5200 images were taken at an accelerating voltage of $1 \mathrm{kV}$ while the higher magnification SEM and TEM images were taken at $30 \mathrm{kV}$. The HD-2000 images were taken at $200 \mathrm{kV}$.

\section{Optical Microscopy:}

The nanorods were examined using an Olympus BX41 optical microscope equipped with a PixeLink digital camera.

\section{Photoluminescence Measurements:}

To measure photoluminescence, the PbS nanocrystal solution and nanorods were excited using a HeNe laser with emission peak at $542 \mathrm{~nm}$. The emissions were then monitored using a spectrometer equipped with an InGaAs Peltier-cooled detector. 


\section{Magnetic Actuation:}

The magnetic nanorods were transferred to a glass slide and suspended in $500 \mu \mathrm{L}$ of distilled water. A horseshoe magnet was moved back and forth along a $90^{\circ}$ arc in an orbit coplanar with the glass slide. The motion of the nanorods under the influence of the fluctuating magnetic field was monitored using the optical microscope and captured in video (see Supplementary Materials).

\section{Supplementary Figures:}

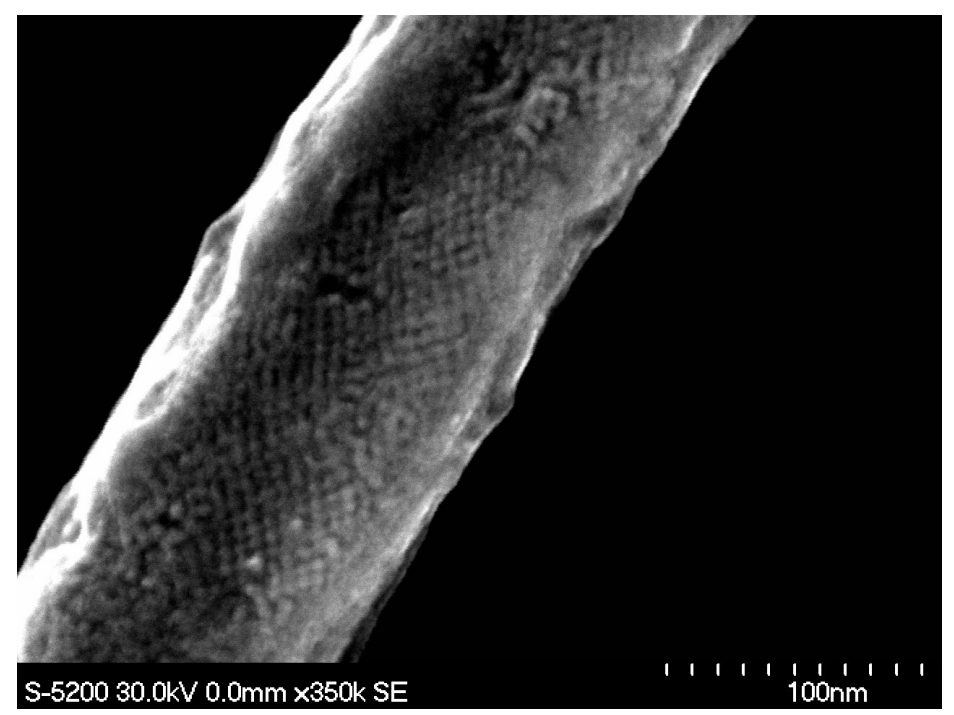

Figure S1: SEM images of PbS nanocrystal nanorods: the nanocrystal building blocks form clearly ordered domains.

\section{Supplementary Video:}

$\mathrm{CoFe}_{2} \mathrm{O}_{4}-\mathrm{PbS}$ mixed nanocrystal nanorods moving with an external magnetic field. The rods are 9 and $11 \mu \mathrm{m}$ long.

\section{References}

1. Cademartiri, L.; Bertolotti, J.; Sapienza, R.; Wiersma, D. S.; Kitaev, V.; Ozin, G. A., J. Phys. Chem. B 2006, 110, (2), 671-673.

2. Sun, S. H.; Zeng, H.; Robinson, D. B.; Raoux, S.; Rice, P. M.; Wang, S. X.; Li, G. X., J. Am. Chem. Soc. 2004, 126, (1), 273-279.

3. Cademartiri, L.; Montanari, E.; Calestani, G.; Migliori, A.; Guagliardi, A.; Ozin, G. A., J. Am. Chem. Soc. 2006, 128, (31), 10337-10346.

4. Kitaev, V.; Ozin, G. A., Adv. Mater. 2003, 15, (1), 75-+. 